\title{
The relationship of neuropsychological functioning to adaptation outcome in adolescents with spina bifida
}

\author{
AMY K. HEFFELFINGER, ${ }^{1}$ JENNIFER I. KOOP, ${ }^{1}$ PHILIP S. FASTENAU, ${ }^{2}$ TIMOTHY J. BREI, ${ }^{3}$ \\ LISA CONANT, ${ }^{1}$ JENNIFER KATZENSTEIN, ${ }^{2}$ SUSAN E. CASHIN, ${ }^{4}$ AND KATHLEEN J. SAWIN ${ }^{5,6}$ \\ ${ }^{1}$ Department of Neurology, Division of Neuropsychology, Medical College of Wisconsin, Milwaukee, Wisconsin \\ ${ }^{2}$ Department of Psychology, Indiana University, Purdue University, Indianapolis, Indiana \\ ${ }^{3}$ Developmental Pediatrics, Riley Hospital for Children, Indiana University School of Medicine, Indianapolis, Indiana \\ ${ }^{4}$ College of Health Sciences, University of Wisconsin-Milwaukee, Milwaukee, Wisconsin \\ ${ }^{5}$ Center Scientist, Self-Management Science Center, College of Nursing, University of Wisconsin-Milwaukee, \\ Milwaukee, Wisconsin \\ ${ }^{6}$ Children's Hospital of Wisconsin, Milwaukee, Wisconsin
}

(Received June 5, 2007; Final Revision May 20, 2008; Accepted May 20, 2008)

\begin{abstract}
Adolescents with spina bifida (SB) vary in their ability to adapt to the disease, and it is likely that numerous risk and protective factors affect adaptation outcomes. The primary aim was to test neuropsychological impairment, exemplified herein by executive dysfunction, as a risk factor in the Ecological Model of Adaptation for Adolescents with SB. Specific hypotheses were that: (1) executive functioning predicts the adaptation outcome of functional independence in adolescents with SB; (2) executive functioning mediates the impact of neurological severity on functional independence; and (3) family and adolescent protective factors are related to functional independence and moderate the relationship between executive functioning and functional independence. Forty-three adolescents aged 12-21 years completed neuropsychological measures and an interview that assessed risk, adolescent and family protective factors, and functional independence. Age, level of lesion, executive functioning, and the protective factor adolescent activities were significantly correlated with the functional independence outcome. In hierarchical regression analysis, the model accounted for $61 \%$ of the variance in functional independence outcomes. Executive functioning mediated the impact of neurological severity on functional independence. (JINS, 2008, 14, 793-804.)
\end{abstract}

Keywords: Myelomeningocele, Meningomyelocele, Cognitive, Cognition, Child, Quality of life

\section{INTRODUCTION}

Spina bifida (SB) remains one of the most prevalent and challenging chronic medical conditions for youth and their families. Resulting from an incomplete closure of the fetal neural tube, it causes damage to the vertebral column, spinal cord, and central nervous system. The most common type of SB, myelomeningocele, occurs when spinal materials protrude from the nonfused vertebrae. The location of the incomplete closure, or the level of the spinal lesion, affects the quality and severity of physical impairments (Fletcher et al., 2005). The most commonly associated phys-

Correspondence and reprint requests to: Amy Heffelfinger, MCW Clinics at Froedtert, 9200 W. Wisconsin Avenue, Milwaukee, WI 53226. E-mail: aheffelfinger@mcw.edu ical impairments include limited mobility, orthopedic problems, varying degrees of paralysis, neurogenic bowel and bladder problems, hydrocephalus, and impaired sensation (Wills et al., 1990). These primary impairments result in secondary problems with physical functional independence, which is the outcome of interest in the present study. However, other secondary difficulties associated with SB include academic, social and psychological problems.

Adolescents with SB exhibit substantial variability in their adaptation to these secondary difficulties. Adaptation is commonly defined as success with the major developmental tasks expected for a person of a given age and gender in the context of the culture, society, and time (Masten \& Coatsworth, 1998; Rutter, 1985, 1987; Stevenson et al., 1997). For adolescents with SB, adaptation includes becoming skilled in disease self-management and use of compensatory strategies for 
difficulties in academic functioning. Poor adaptation during adolescence places individuals at risk for continued problems in adulthood, such as underemployment, unemployment, limited independence, poor self-esteem, and reliance on federal and state support programs (Abramson et al., 1979). Thus, identifying factors associated with successful adaptation may increase the likelihood of positive outcomes for individuals with SB.

Adaptation research has primarily focused on the relationship of neurological severity to outcomes. However, successful adaptation of all adaptation outcomes is not likely to be solely dependent upon the condition's neurological severity. In studies comparing adolescents with SB with comparable severity, substantial variability has been found in functional, mental health and quality of life outcomes (Abramson et al., 1979; Bowman et al., 2001; Holmbeck \& Faier-Routman, 1995; Hunt et al., 1999; Hunt \& Poulton, 1995; King et al., 1993). Despite this recognized variability in adaptation, little research has examined possible variables that may influence the relationship of neurological status to adaptation outcomes.

\section{ECOLOGICAL MODEL OF ADAPTATION FOR ADOLESCENTS WITH SPINA BIFIDA}

To guide research of possible mediating factors, Sawin and colleagues (2003b) developed the Ecological Model of Adaptation for Adolescents with SB. The rationale and validity of this model were presented previously (Sawin et al., 2003a). In analyses using interview and clinical data only, differing patterns of relationships between risk and protective factors with outcomes were identified (Sawin et al., 2002, 2003a). Correlational analysis supported the relationship of (a) SB severity factors and adolescent activities to functional independence and self-management out- comes and (b) adolescent beliefs and family resourcefulness variables to developmental competence and quality of life.

Components of the model examined in this study are presented in Figure 1. The model includes three risk categories and two protective categories hypothesized to influence the adaptation outcomes of functional independence. Driven by existing literature, the proposed risk factors include (a) neurological severity, (b) individual and family characteristics, and (c) neuropsychological functioning, exemplified in the current study by executive functioning. The protective factors examined within this study include (a) adolescent resilience and (b) family resourcefulness.

\section{Risk Factors for Poor Adaptation}

Neurological severity indices of SB, such as level of lesion, shunted hydrocephalus, shunt infections, shunt revisions, and presence of epilepsy are important predictors of adaptation outcomes (Barf et al., 2003; Bergsten \& Lagergren, 1990; Duquette, 1997; Fletcher et al., 2005; Iddon et al., 2004; Kim, 1991; Larsson, 1995; Matson et al., 2005; Pless, 1984; Shurtleff, 2000; Wallander \& Thompson, 1995; Wallander \& Varni, 1995; Wolman et al., 1994; Zurmohle et al., 1998). Level of lesion affects the quality and severity of motor and sensory impairment (Galli et al., 2002). In general, the higher level of spinal cord lesion is associated with a greater number of brain abnormalities involving the tectum, posterior fossa, pons, falx, cerebellar hemispheres, and splenium of the corpus collosum, as well as smaller brain volume overall (Aldrich et al., 1992; Fletcher et al., 2005; Wills et al., 1990).

This heterogeneity in neurological sequelae has been associated with variability in neuropsychological outcomes. For example, the presence of shunted hydrocephalus and subsequent shunt revisions are associated with poorer outcome

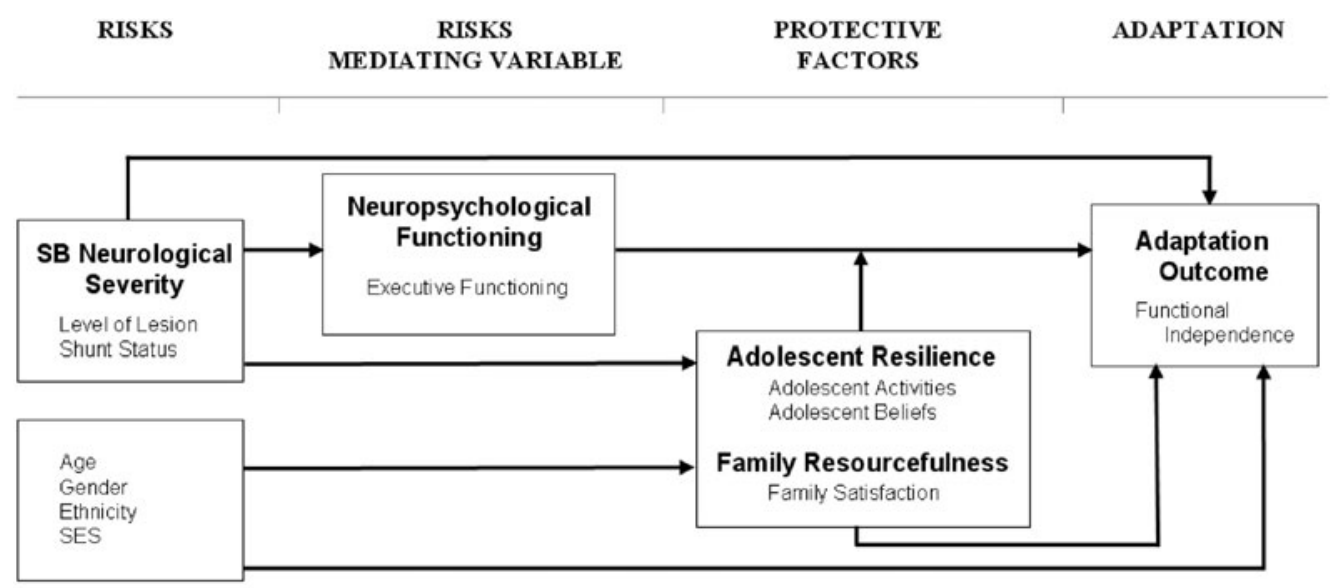

Note: The bold labels indicate the components of the model. The specific measures of the model components are unbolded.

Fig. 1. The ecological model of adaptation for adolescents with spina bifida. 
(Dennis et al., 2006). Higher lesion levels are associated with greater neuropsychological impairment (Fletcher et al., 2005; Lomax-Bream et al., 2007). Unfortunately, it remains unclear as to how the presence or absence of other risk or protective factors influences the impact of these neurological factors on neuropsychological functioning.

Individual and family characteristics have been associated with negative adaptation (Fletcher et al., 2005). Lower socioeconomic status (SES) is a powerful predictor, especially of poor language and social competence. Additionally, age relates to outcomes with improvement in self-care skills as children get older (Msall et al., 1994; Ziviani et al., 2001).

A distinctive neuropsychological pattern exists (Dennis et al., 2006). Stronger language functioning, despite pragmatic language difficulty, is often present relative to poorer nonverbal performance and perceptual skills (Dennis, 1985; Fletcher et al., 1992, 2005; Snow et al., 1994; Yeates et al., 1995). Impairments in attention (Davidson et al., 2006; Fennell et al., 1987; Loss et al., 1998) and executive functioning (Burmeister et al., 2005; Iddon et al., 2004) have been well documented, along with processing speed, visualmotor integration, and oculomotor (Donders et al., 1991; Thompson et al., 1991) learning and memory (Prigatano et al., 1983; Scott et al., 1998), and arithmetic deficits (Barnes et al., 2006; Dennis \& Barnes, 2002; Friedrich et al., 1991; Wills et al., 1990). The core cognitive deficits of SB emerge in infancy, persist throughout life, and are present regardless of IQ (Dennis et al., 2006).

The neuropsychological battery used in this study examined numerous domains, all of which undoubtedly interact to affect broader adaptive outcomes. However, in the current preliminary test of the model, the domain of executive functioning, which involves efficiently monitoring and regulating behaviors, was selected as the exemplary neuropsychological function. Executive functioning impairments in individuals with SB have been found within the areas of planning, organization, goal-directed behavior, and problem solving (Fletcher et al., 1996; Snow et al., 1994). A few studies have demonstrated difficulties in initiating behavior and mental flexibility (Burmeister et al., 2005; Duquette, 1997; Snow, 1999). In another study, all participants had difficulty with mental flexibility, efficiency of processing, conceptualization, or problem solving regardless of intellectual level (Dise \& Lohr, 1998). These abilities are thought to be necessary for adaptation, especially in terms of social competence, adjustment to adulthood, and higher academic attainment (Bergsten \& Lagergren, 1990).

Executive dysfunction is likely to become progressively more problematic in adolescence and early adulthood because of increased need for independent problem solving. Data from multiple studies suggest that executive functioning deficits are prevalent in adolescents with SB and play a prominent role in the adolescent's ability to succeed at school, learn self-care, and master social skills (Fletcher et al., 1996; Iddon et al., 1996; Landry et al., 1993; Snow, 1999). However, the impact of these deficiencies on adaptation has yet to be systematically examined.

\section{Protective Factors}

Adolescent resilience, the personal attributes facilitating an adolescent's ability to manage stressors and achieve a positive outcome, is a function of adolescents' aggregate resources, strengths, beliefs, and skills (Masten \& Coatsworth, 1998). In adolescents with chronic conditions (Resnick \& Hutton, 1987; Sawin \& Marshall, 1992; Sawin et al., 1996), resiliency factors including decision-making, household responsibility, future expectations, coping strategies, and hope were variably related to developmental outcomes. For adolescents with SB specifically, Resnick and Hutton (1987) found that individuals who had any household responsibility beyond self-care had greater selfesteem and positive body image regardless of severity of illness. However, adolescents with SB generally have poorer autonomy and decision-making skills (Monsen, 1992) and less hope (Voll et al., 1995) than healthy controls (Davis et al., 2006), likely contributing to their increased risk for poor adaptation.

Family resourcefulness is a particularly important factor for the success of children with chronic illnesses (McCubbin et al., 1996). Characterizing how a family typically appraises, operates and/or behaves (Zauszniewski, 1995), these attributes include family satisfaction, activities, problem solving, hardiness, adaptability, individuation, and cohesion. In a study involving children with chronic epilepsy, the family variable moderated the effect of neuropsychological functioning on academic achievement (Fastenau et al., 2004). Similarly, in children with SB, parent's stress, psychosocial adjustment, and marital satisfaction were found to predict children's psychological outcomes (Friedrich et al., 1991). Adolescents with SB from families that encouraged independence, treated the adolescent in an age-appropriate manner, and did not overprotect the adolescent, were more likely to have positive adaptation outcomes (Aldrich et al., 1992; Loomis et al., 1997; McAndrew, 1979; Pless, 1984). Family satisfaction, an individual's belief that their family is functioning in a satisfactory and supportive manner, captures an important component in family resourcefulness (Austin \& Huberty, 1989; Smilkstein et al., 1982), and is included as a possible protective factor in the current study.

The model developed by Sawin and colleagues (2003b) proposes that risk factors, such as neuropsychological impairments, and protective factors, such as those identified above, interact to influence functional independence. The model predicts a moderating relationship. It is suspected that for adolescents with poorer executive functioning, protective factors influence functional independence such that higher adolescent resilience, hope, and family satisfaction will protect from the negative impact of neuropsychological impairments.

\section{HYPOTHESES OF THE CURRENT STUDY}

Based on the Ecological Model of Adaptation for adolescents with SB (Sawin et al., 2002, 2003b), previous analyses 
have evaluated the relationship of individual and family characteristics, neurological severity, adolescent protective factors and family protective factors to the adaptation outcomes of functional independence, self-esteem, and health-related quality of life. However, the relationship of neuropsychological variables with the other variables in the model has not yet been explored. Because of the proposed reliance on executive functioning for adaptation outcomes, the role of executive functioning was specifically explored in this model. Thus, the primary aim of the current study was to test the relationship of neuropsychological functioning, exemplified by executive functioning, to other variables within the Ecological Model of Adaptation. Specific hypotheses were that: (1) executive functioning predicts the adaptation outcome of functional independence in adolescents with SB; (2) executive functioning mediates the impact of neurological severity on functional independence; and (3) family and adolescent protective factors are related to functional independence and moderate the relationship between executive functioning and functional independence.

\section{METHODS}

The current analysis is a part of a larger study of adaptation in SB. Qualitative data, descriptions of protective and outcome variables, and relationship of protective factors to outcomes have been previously reported (Buran et al., 2004; Sawin et al., 2002, 2003a,b, 2006). Therefore, only procedures directly relating to the current study questions are presented here. The project was approved by the Internal Review Board at Indiana University Purdue University Indianapolis and University of Wisconsin - Milwaukee. The research was conducted in accordance with the Helsinki Declaration.

\section{Sample}

Funding for neuropsychological testing was obtained after the recruitment period began for the parent study, hence only available for $2 / 3$ of the total participant sample. Fortyfive participants from the larger study $(n=66)$ completed a neuropsychological battery and an interview that assessed SB risk, adolescent and family protective variables and adaptation outcome. Two of the 45 were excluded due to incomplete data resulting in analyses on 43 participants. These 43 participants did not differ from the remaining 23 on functional independence, gender, ethnicity, parent education level, level of lesion, or shunt status. Within this subsample, ages ranged from 12 to 21 years $(M=15.67$; $S D=2.4)$, $56 \%$ were female, and $9 \%$ were of ethnic minority status. Additional demographic and clinical variables are presented in Table 1. To obtain information on behavior problems in the sample, the parents of 40 participants completed the Achenbach Child Behavior Checklists (Achenbach and Rescorla, 2001). Two adolescents had clinically significant symptoms on the Withdrawn Problems
Table 1. Demographic and clinical data

\begin{tabular}{|c|c|c|c|}
\hline \multicolumn{4}{|c|}{ Demographic data $(n=43)$} \\
\hline & $\%$ & $M$ & $S D$ \\
\hline Age & & 15.76 & 2.42 \\
\hline $\mathrm{IQ}^{\mathrm{a}}$ & & 90.65 & 15.82 \\
\hline \multicolumn{4}{|l|}{ Gender } \\
\hline Female & 55.8 & & \\
\hline Male & 44.2 & & \\
\hline \multicolumn{4}{|l|}{ Ethnicity } \\
\hline Caucasian & 90.7 & & \\
\hline Non-Caucasian & 9.3 & & \\
\hline \multicolumn{4}{|c|}{ Clinical data } \\
\hline \multicolumn{4}{|l|}{ Level of Lesion ${ }^{b}$} \\
\hline Thoracic/lumbar (T10-T12) & 27.9 & & \\
\hline Lumbar & 37.2 & & \\
\hline Lumbosacral & 16.3 & & \\
\hline Sacral & 16.3 & & \\
\hline Other & 2.3 & & \\
\hline \multicolumn{4}{|l|}{ Shunt present } \\
\hline Yes & 82.2 & & \\
\hline No & 17.8 & & \\
\hline Number of revisions ${ }^{c}$ & & 1.70 & 1.58 \\
\hline
\end{tabular}

scale, one on Anxious/Depressed Problems scale, and five on the Attention Problems scale.

\section{Procedures}

Both parent consent and adolescent consent/assent were obtained. Parents and adolescents completed an interview in the home or via telephone regarding medical history, demographics, psychosocial functioning, and family factors. Variables of interest collected for the current study were age, SES (mother's education), gender, neurological severity [level of lesion (LOL) and shunt status], family and adolescent protective factors of adolescent resilience (activities and beliefs), and family resourcefulness (parental report of family satisfaction). The outcome measure of interest in this study was functional independence.

Families were also invited to participate in the neuropsychological testing component of the study at the laboratory. The test battery was designed to screen various aspects of neuropsychological functioning previously identified as domains affected by SB, including executive functioning, as well as processing speed, attention, visual spatial, language, memory, and academic functioning. Data on processing speed, attention, and executive functioning were available for 43 participants. Executive functioning was chosen as the domain of interest in the current analyses based on the hypothesized relationship between executive functioning and adolescent functional independence. 


\section{Measures}

\section{Neurological severity}

Data for LOL was abstracted by one investigator based on movement against gravity (Bartonek et al., 1999; Unified Data Systems, 2000). The vast majority of those in the sample had hydrocephalus. The shunt status variable was scored 0 if the individual had no shunt and 1 plus the number of revisions for all others.

\section{Neuropsychological functioning}

Neuropsychological tests of various domains were selected based on the theoretical understanding of each measure. The Kaufman Brief Intelligence Test (KBIT) was administered to determine cognitive ability (Kaufman \& Kaufman, 1990). Executive functioning measures were selected from a previous study that found that adolescents with spina bifida were compromised on their executive skills (Snow, 1999): (1) Wisconsin Card Sorting Test (WCST; Heaton et al., 1993) assesses the degree one can think abstractly, generate solutions to a problem, and flexibly shift from one solution to another as the demands of the task change. (2) Trail Making Test (TMT; Reitan \& Wolfson, 1992) consists of Part A, assessing processing speed to connect a series of dots following numerical order, and Part B requiring cognitive flexibility to connect an alternating pattern of numbers and letters. Because procedures and normative data for the TMT differ significantly for younger adolescents and older adolescents or young adults, the Intermediate Child/ Adolescent Form (normed for 9-14 years) was used for all ages. Older adolescents were compared with norms from the oldest age group at which point it was believed that scores were stabilizing and reaching asymptote. This supposition was confirmed with inspection of the data. To assess processing speed, the Symbol Search subtest of the Wechsler Intelligence Scale for Children - 3rd Edition (WISCIII; Wechsler, 1991) which involves speeded visual scanning in search of a target symbol, was administered. The 16-yearold normative data were applied to adolescents 17-20 years old. Attention was assessed using the Conners' Continuous Performance Test (CPT; Conners, 1995) which requires the child to sustain visual attention to detect infrequently occurring targets, and inhibit task-inappropriate responses.

\section{Protective factors}

Each measure of adolescent and family protective factors has evidence of reliability and validity. Higher scores reflect higher level of the concept. Adolescent Resilience was measured by Adolescent Decision-making (DM) and Chores subscales of the Adolescent Activity Inventory (Buran et al., 2004), which assesses participation on decisions such as choosing friends, choosing clothes, and making rules for homework and curfews as well as involvement in chores such as cleaning own bedroom, doing dishes, and performing pet care. The Snyder Hope Scale (Snyder et al., 1991) captures the adolescents' hope for the future and their perception of their ability to achieve their hopes related to life success. Family satisfaction with family functioning was measured using parent report on the Family APGAR (Smilkstein, 1993). Each of these measures has been related to outcomes for adolescents with chronic conditions (Fastenau et al., 2004; Sawin \& Marshall, 1992)

\section{Outcome measure}

Functional independence was measured using adolescent report on the WeeFIM ${ }^{\circledR}$ instrument, a standardized and agenormed measure of functional status which has established reliability and validity (Msall et al., 1994). The instrument delineates seven levels of assistance needed for self-care (e.g., eating, grooming, bowel/bladder), mobility (e.g., transfers, ambulation), and cognition (e.g., problem solving, memory, communication).

\section{Data Analysis}

To control for Type I error, composite scores were created for some variables based on (1) theoretical considerations of underlying constructs, (2) relationship with outcome, and (3) significant correlations with each other. For example, WCST total error and TMT Part B were combined to create an Executive Functioning composite on the basis that both are sensitive to executive dysfunction (Amieva et al., 1998; Romine et al., 2004), were significantly correlated with functional independence, and were significantly inter-correlated (Table 2). The following three neuropsychological composites were created: Executive Functioning (WCST \% Total Errors, TMT Part B), Processing Speed (WISC-III Symbol Search, CPT Hit Rate, TMT Part A), and Attention (CPT Omissions, CPT Variability Index). Attention, Processing Speed, and Executive Functioning composites were highly correlated, showing the same general pattern of correlations with the outcomes. Due to multicollinearity, only the neuropsychological composite Executive Functioning was analyzed, because it was hypothesized to relate to functional independence as well as being highly correlated with the outcome variable. Two adolescent activity measures (decision-making and chores) were combined to make an Adolescent Activities Composite. Composites were created by taking the average of their components. Individual measure scores of neurological severity, adolescent beliefs, family satisfaction, and functional status were used for the analysis.

One-tailed correlations were calculated between risk factors, protective factors, and functional independence to determine which variables were related. Pearson $r$ was calculated for correlations involving two continuous variables, whereas Spearman's rho was calculated for correlations involving nominal and ordinal variables. Only factors that were significantly correlated with functional independence were considered appropriate for the regression analyses.

Multiple regression analysis design for the functional independence outcome was based on the Ecological Model of 
Table 2. Intervariable correlations between cognitive variables and functional independence

\begin{tabular}{|c|c|c|c|c|c|c|c|c|c|c|c|c|}
\hline & K-BIT & $\begin{array}{c}\mathrm{EF} \\
\mathrm{COMP}\end{array}$ & $\begin{array}{l}\text { WCST } \\
\text { errors }\end{array}$ & $\begin{array}{c}\text { TMT } \\
\text { Part B }\end{array}$ & $\begin{array}{l}\text { ATT } \\
\text { COMP }\end{array}$ & $\begin{array}{l}\mathrm{CPT} \\
\mathrm{Om}\end{array}$ & $\begin{array}{l}\text { CPT } \\
\text { Var }\end{array}$ & $\begin{array}{c}\text { PS } \\
\text { COMP }\end{array}$ & $\begin{array}{l}\text { Sym } \\
\text { Srch }\end{array}$ & $\begin{array}{l}\text { CPT } \\
\text { RT }\end{array}$ & $\begin{array}{r}\text { TMT } \\
\text { Part A }\end{array}$ & $\begin{array}{l}\text { Func } \\
\text { Ind }\end{array}$ \\
\hline K-BIT & 1.00 & & & & & & & & & & & \\
\hline EF COMP & $.62 * * *$ & 1.00 & & & & & & & & & & \\
\hline $\begin{array}{l}\text { WCST Total } \\
\text { Errors }\end{array}$ & $.54 * * *$ & $.73 * * *$ & 1.00 & & & & & & & & & \\
\hline TMT Part B & $.51 * * *$ & $.91 * * *$ & $.37 * *$ & 1.00 & & & & & & & & \\
\hline ATT COMP & $.51 * * *$ & $.55 * * *$ & $.42 * *$ & $.47 * *$ & 1.00 & & & & & & & \\
\hline CPT Omissions & $.51 * * *$ & $.56 * * *$ & $.40 * *$ & $.50 * *$ & $.82 * * *$ & 1.00 & & & & & & \\
\hline CPT Variability & $.37 * *$ & $.39 * *$ & $.33 * *$ & $.32 *$ & $.88^{* * * *}$ & $.45^{* *}$ & 1.00 & & & & & \\
\hline PS COMP & $.44 * *$ & $.75 * * *$ & $.56^{* * * *}$ & $.67 * * *$ & $.64 * *$ & $.47 * *$ & $.61 * * *$ & 1.00 & & & & \\
\hline Symbol Search & $.64 * * *$ & $.70 * * *$ & $.45^{* *}$ & $.66^{* * *}$ & $.57 * * *$ & $.51 * * *$ & $.47 * *$ & $.84 * * *$ & 1.00 & & & \\
\hline CPT RT & .26 & $.28 *$ & $.38 * *$ & .13 & $.45^{* *}$ & -.10 & $-.61 * * *$ & $.68 * * *$ & $.39 * *$ & 1.00 & & \\
\hline TMT Part A & $.52 * * *$ & $.67 * * *$ & $.37 * *$ & $.67 * * *$ & $.48^{* *}$ & $.46^{* *}$ & $.37 * *$ & $.66^{* * * *}$ & $.53 * * *$ & .24 & 1.00 & \\
\hline $\begin{array}{l}\text { Functional } \\
\text { Independence }\end{array}$ & .22 & $.48 * *$ & $.27^{*}$ & $.48 * *$ & $.27 *$ & $.39 * *$ & .10 & $.44 * *$ & $.45^{* *}$ & .14 & $.48^{* *}$ & 1.00 \\
\hline
\end{tabular}

Note. All comparisons were one-tailed and Pearson's $r$ statistics. K-BIT $=$ Kaufman Brief Intelligence Test; EF COMP $=$ Executive Functioning Composite; ATT COMP = Attention Composite; CPT Om = CPT Omissions; CPT Var = CPT Variability; PS COMP = Processing Speed Composite; Sym Srch $=$ Symbol Search; CPT RT $=$ CPT Reaction Time; Func Ind = Functional Independence.

$* p<.05, * * p<.01, * * * p<.001$.

Adaptation for Adolescents with SB (see Figure 1). In the first two steps, the demographic and neurological severity risk factors that correlated with functional independence were entered, respectively. In the third step, executive functioning was entered. Each variable was considered to account for a meaningful portion of the outcome variance if it was significant at $p<.05$ level. For the purposes of this analysis, any variable with $p<.10$ was also retained as a potential contributor to the outcome because of the small sample size and exploratory nature of hypotheses. Variance Inflation Factor and Tolerance Tests of multicollinearity were not significant.

To test for the mediation of executive functioning, there had to be a relationship between (1) the SB neurological severity variable and executive functioning, (2) the SB neurological severity variable and functional independence, and (3) executive functioning and functional independence (Baron \& Kenny, 1986). The Sobel test (1982) was conducted to test for significant mediating effects of the neuropsychological variables, as indicated by a significant reduction in the association between SB neurological severity and adaptation outcome when executive functioning was added to the regression model. An additional regression analysis was conducted including the interaction term of executive functioning and family and adolescent protective factors to determine whether family and adolescent protective factors had a moderating effect on the relationship between executive functioning and functional independence.

\section{RESULTS}

Descriptive statistics were calculated for each variable and composite score (Table 3). Initial examination of the distri- bution of the data revealed that the TMT Part B variable had two low outlier values. To maximize sample size, the outlier values were replaced with imputed values based on regression on other related scores (TMT Part A, KBIT IQ). This also helped to normalize the shape of the distribution. Primary regression analyses were re-run excluding the two outlying cases and confirmed that the imputed variables did not alter the results.

The sample generally demonstrated low average executive functioning with mean scores falling within $1 S D$ of the normative mean. Participants were hopeful and generally satisfied with their families, but they had fairly low adolescent activities scores, adolescent participation in decisionmaking, and the chores scale reflected few household responsibilities. The sample's average level of functional independence as measured by the WeeFIM indicated the need for limited assistance in activities of daily living.

\section{Variables Associated with Adaptation Outcomes}

Results of correlational analyses are presented in Table 4. Age $(r=.58)$, level of lesion $(r=.72)$, executive functioning $(r=0.48)$, and the protective factor adolescent activities $(r=.76)$ were significantly correlated with the Functional Independence outcome $(p<.01)$. In other words, being older, having a lower lesion level, having higher executive functioning skills, and being involved in more activities all relate to being more functionally independent. Although IQ, shunt status, SES, gender, Adolescent Hope, and Family Satisfaction were originally included in the model, there were no significant relationships with functional independence so they were omitted from any further analyses. 
Table 3. Descriptive data for variables

\begin{tabular}{|c|c|c|c|c|}
\hline \multicolumn{5}{|c|}{ Executive functioning } \\
\hline Domain & $M$ & $S D$ & Minimum & Maximum \\
\hline Executive Functioning Domain ${ }^{a}$ & 89.53 & 18.82 & 46.83 & 124.0 \\
\hline Trail Making Test Part B & 86.45 & 27.62 & 7 & 114 \\
\hline Wisconsin Card Sorting Test \% Total Errors & 92.60 & 17.25 & 63 & 128 \\
\hline Processing Speed Domain & 93.54 & 16.33 & 31 & 124 \\
\hline Symbol Search & 90.71 & 17.48 & 55 & 130 \\
\hline CPT Reaction Time & 96.21 & 18.13 & 52 & 121 \\
\hline Trail Making Test Part A & 98.72 & 13.50 & 68 & 126 \\
\hline Attention Domain & 88.62 & 23.61 & 54 & 120 \\
\hline CPT Omissions & 89.01 & 16.58 & 65 & 118 \\
\hline CPT Reaction Time Variability & 88.22 & 20.31 & 42 & 136 \\
\hline \multicolumn{5}{|c|}{ Adolescent resilience } \\
\hline Activities $^{\text {b }}$ & .04 & .86 & -1.87 & 2.18 \\
\hline Decision Making ${ }^{\mathrm{c}}$ & 3.81 & .92 & 2.00 & 5.72 \\
\hline Chores $^{c}$ & 1.63 & .31 & 1.00 & 2.40 \\
\hline \multicolumn{5}{|l|}{ Secondary conditions/adaptation outcome } \\
\hline Functional Independence (WeeFIM ${ }^{\circledR}$ Instrument $^{\mathrm{d}}$ & 106.18 & 18.72 & 55.00 & 126.00 \\
\hline
\end{tabular}

Note. All scores in Standard Scores $(M=100, S D=15)$ unless otherwise indicated.

${ }^{\mathrm{a} C}$ Composite created as the average of standard scores.

${ }^{\mathrm{b}}$ Composite created as the average of $z$ scores.

'Raw scores.

${ }^{\mathrm{d}}$ WeeFIM ${ }^{\circledR} 18$-item scale.

Table 4. Intervariable correlations

\begin{tabular}{|c|c|c|c|c|c|c|c|c|c|}
\hline \multirow[t]{2}{*}{ Model variables } & \multicolumn{3}{|c|}{ Demographics } & \multirow{2}{*}{$\begin{array}{c}\begin{array}{c}\text { Neurological } \\
\text { severity }\end{array} \\
\begin{array}{c}\text { Level of } \\
\text { Lesion }\end{array}\end{array}$} & \multirow{2}{*}{$\begin{array}{c}\begin{array}{c}\mathrm{NP} \\
\text { functioning }\end{array} \\
\text { EF Comp }\end{array}$} & \multicolumn{3}{|c|}{$\begin{array}{c}\text { Family and adolescent } \\
\text { protective factors }\end{array}$} & \multirow{2}{*}{$\begin{array}{c}\begin{array}{c}\text { Adaptation } \\
\text { outcome }\end{array} \\
\begin{array}{c}\text { Funct } \\
\text { Indepen }\end{array}\end{array}$} \\
\hline & Age & Gender & SES & & & $\begin{array}{c}\text { Adol } \\
\text { Activities }\end{array}$ & $\begin{array}{l}\text { Adol } \\
\text { Hope }\end{array}$ & $\begin{array}{l}\text { Family } \\
\text { Satis }\end{array}$ & \\
\hline Age & 1.00 & & & & & & & & \\
\hline Gender & -.05 & 1.00 & & & & & & & \\
\hline SES & .07 & .07 & 1.00 & & & & & & \\
\hline Level of Lesion & $.37 * *$ & $.31 *$ & .14 & 1.00 & & & & & \\
\hline EF Comp & .17 & .03 & .21 & $.35^{*}$ & 1.00 & & & & \\
\hline Adol Activities & $.68^{* *}$ & .11 & .06 & $.61 * *$ & $.38 * *$ & 1.00 & & & \\
\hline Adol Hope & .09 & .06 & .21 & .12 & .21 & .19 & 1.00 & & \\
\hline Family Satis & -.24 & .08 & .15 & .08 & .05 & -.13 & $.51 * *$ & 1.00 & \\
\hline Funct Indepen & $.58 * *$ & .04 & .24 & $.72 * *$ & $.48 * *$ & $.76 * *$ & -.08 & -.24 & 1.00 \\
\hline
\end{tabular}

Note. All comparisons were one-tailed. EF comp = Executive Function Composite; Family Satis = Family Satisfaction; Funct Indepen $=$ Functional Independence; Spearman's Rho statistics, all others Pearson's $r$.

$* p<.05, * * p<.01$.

\section{Neuropsychological Variables and Functional Independence Outcome}

The criteria delineated by Baron and Kenny (1986) regarding possible mediation were met for the relationship between neurological severity and functional independence by executive functioning. For the primary regression (see Table 5), both age $(p=.001)$ and level of lesion $(p=.002)$ were significant in the first and second steps. In the third step, when executive functioning was entered, it accounted for a significant proportion of the variance $(p=.013)$, and level of lesion remained significant but its significance was somewhat reduced $(p=.02)$. This total model accounted for $51 \%$ of the variance in functional independence. This pattern of findings suggested that executive functioning may at least partially mediate the impact of neurological severity on functional independence. To test this possibility, the Sobel test (1982) was performed and found to be signifi- 
Table 5. Summary of hierarchical regression analysis for prediction of functional independence by executive functioning

\begin{tabular}{lcccc}
\hline \multicolumn{1}{c}{ Variable } & $\boldsymbol{\Delta} \mathbf{F}$ & $\operatorname{adj} \Delta \mathbf{R 2}$ & $\boldsymbol{p}$ for $\boldsymbol{\Delta}$ & Beta \\
\hline $\begin{array}{l}\text { Step 1 } \\
\text { Age }\end{array}$ & 20.21 & 0.31 & $<.001$ & $0.58^{* * *}$ \\
Step 2 & & & & \\
$\quad$ Age & & & & $0.42^{* *}$ \\
$\quad$ Level of Lesion & 10.97 & 0.13 & .002 & $0.41^{* *}$ \\
Step 3 & & & & \\
$\quad$ Age & & & & $0.40^{* *}$ \\
$\quad$ Level of Lesion & & & & $0.31^{*}$ \\
$\quad$ Executive Function & 6.76 & 0.07 & .013 & $0.30^{*}$ \\
\hline \hline
\end{tabular}

$* p<.05, * * p<.01, * * * p<.001$.

cant, supporting the mediating effect for executive functioning $(z=1.95 ; p=.05)$.

To test for a possible moderating effect of adolescent activities on the relationship between executive functioning and functional independence, a separate series of regressions were conducted. Centered scores for executive functioning, adolescent activities, and the interaction between the two were regressed on functional independence. Executive functioning accounted for a significant proportion of the variance $(p<.001)$ when entered in the first step and was slightly reduced $(p<.05)$ when adolescent activities was entered in the second step $(p<.001)$. The interaction term was not significant, however $(p=.147)$, with the effect of executive functioning being slightly reduced ( $p=$ $.055)$ and adolescent activities continuing to account for a substantial proportion of the variance $(p<.001)$. These results suggest that adolescent activities may have a direct effect on functional independence, but do not significantly moderate the relationship between executive functioning and functional independence.

Because attention (Burmeister et al., 2005; Davidovitch et al., 1999; Fennell et al., 1987; Loss et al., 1998) and processing speed deficits (Donders et al., 1991; Thompson et al., 1991) have also been implicated in SB, post hoc analyses were conducted on these composites. Repeating the regression models yielded similar results for the Processing Speed Composite.

\section{DISCUSSION}

This study was an initial step in testing neuropsychological variables in the Ecological Model of Adaptation for Adolescents with SB, proposing that aspects of an adolescent's life, including risk factors (demographic characteristics, SB neurological severity, neuropsychological functioning) as well as protective factors (adolescent resilience and family resourcefulness), play a role in adaptation outcomes (functional independence). The results of this study mostly support the proposed hypotheses. Age and SB neurological severity (as measured by level of lesion) both account for a significant amount of variability in functional independence, and the relationship between level of lesion and functional independence is partially mediated by executive functioning. Thus, the level of the spinal lesion partially exerts its influence on executive functioning abilities which in turn influence the adolescents' functional status. It appears that the level of lesion has a direct effect as well, although causation could not be evaluated with this design. Level of lesion clearly influences numerous aspects of functioning (Fletcher et al., 2005; LomaxBream et al., 2007), and this study further suggests that the higher the lesion on the spinal column the greater the negative impact on adolescent functional independence. This is likely due, in part, to the motor impairment reflected by the LOL. In SB, the higher the LOL the larger the motor deficit. Including LOL removes some of the variance due to motor proficiency on functional status. Higher lesions also negatively impact executive functioning which further impacts functional independence.

The hypothesis proposing the moderating role of protective factors was not supported. Although protective mechanisms of adolescent resilience, namely adolescent activities and chores, are related to functional independence, they do not interact with executive functioning to exert this influence as predicted in the model. In previous studies some protective factors have been shown to moderate or buffer the impact of risk factors on adolescent outcomes (e.g., high risk behaviors, depression). That is these factors provide protection for those in specific high risk categories (i.e., poverty, previous abuse, chronic illness; Bernat \& Resnick, 2006). However, other protective factors appear to facilitate independence regardless of risk (e.g., family or school connectedness, attitudes, grade point average) reducing the occurrence of negative outcomes for all adolescents, not just those with high risk (Resnick et al., 2004). Date from this study would indicate that the activities and chores have a protective influence on functional independence for all adolescents, not just those with impaired neuropsychological functioning.

These results shed light on the complexities inherent in attempting to understand adaptive outcomes associated with SB. In this study, the adaptive outcome of functional independence was a measure of how much assistance the adolescent needed in functioning with regard to self-care, mobility and cognitive functions. As would be expected on the basis of previous studies, an adolescent's age and the level of lesion appeared to be related to functional status. The current results also suggest that weaknesses in executive function mediated the negative consequences of a higher level of lesion on functional status. Effective management of self-care activities undoubtedly requires some degree of executive functioning. The self-care activities necessary with SB are numerous and often complex, including the need to remember and monitor catheterization schedules, pressure release, wound care, among others. Not only must an adolescent plan to complete these activities on schedule, but they must do so in numerous situations. The inherent desire an adolescent with SB has to normalize their medical situ- 
ation from their peers' perspective demands that they engage in these activities in a manner that is as minimally disruptive as possible. The current results also suggest that higher levels of adaptive functioning are achieved when an adolescent is more involved in activities and chores.

The proposed ecological model suggests that multiple factors influence the adaptation outcomes in adolescents with SB. The results of this study support many aspects of the proposed model and strongly suggest that, while disease characteristics and age do influence adaptation outcomes, neuropsychological functions may mediate the relationships between these variables. Clearly, studies with larger sample sizes and more comprehensive assessments are needed to more definitively test the relationships, but several tentative conclusions can be made from the current results. First, the adaptation outcome of functional independence is significantly influenced by age, level of lesion, executive functioning, and adolescent activities. Higher levels of objectively measurable functions, such as executive functioning and involvement in activities and chores seem to result in higher functional independence. Second, executive functioning mediates the relationship between level of lesion and functional independence, as predicted. The model also predicts that neuropsychological functioning and adolescent activities have an interaction effect on functional independence. The present data, however, suggested a direct effect of adolescent activities on functional independence, regardless of neuropsychological functioning.

The study was limited by the small sample, the convenience nature of the sample, lack of ethnic and geographical diversity, lack of systematic evaluation of clinical psychiatric diagnoses such as ADHD, and limited range of disease severity as most participants had higher level lesions. The model is complex and to fully test the relationship of model components, a larger sample will be needed. The cross sectional design prevents further understanding of the causality suggested in the model, and further studies should include a longitudinal component.

The current analysis focused on executive functioning as an example of neuropsychological functioning in the Ecological Model of SB, executive functioning did not have a unique association with the outcomes. Rather, its pattern that was replicated across other neuropsychological domains, especially processing speed. Further work needs to determine which cognitive processes mediate neurological severity effects on functional outcomes.

It also is likely that other risk factors, such as neurological severity markers of hydrocephalus, shunt status, epilepsy and muscle strength may relate to functional independence differently than level of lesion. In the model, adaptation outcomes are defined more broadly than functional independence. It is suspected that outcomes definitions and inclusions of assessment measures will influence which risk and protective factors have an impact. For example, the WeeFIM ${ }^{\circledR}$ composite did not allow further breakdown of the types of adaptation outcomes. Future studies are needed to further investigate these complex relationships. Thus, future studies will need to include larger samples, longitudinal design, more variables to better represent the model constructs, and path analysis to investigate the complexity of this model.

\section{Clinical Significance}

These findings have implications for patient care and future research. If future studies support these findings, programs of care for adolescents with SB should include direct training executive functioning as well as compensatory strategies. Treatment could address functional self-management and chore and activity involvement, providing These results provide a foundation for interventions that will enable these youth to make a successful transition to independent living and vocational productivity (West et al., 1995).

\section{ACKNOWLEDGMENTS}

This project was funded in part by the Clarian Health Partners, American Association of Spinal Cord Injury Nurses, NIH Institutional National Research Service Award \# 5 T32 NR07066, and MCHB's Leadership Education in Adolescent Health, Indiana University. In addition, the authors thank Janet Kain, Susan Modlin, Vanessa Patrick, Brenna LeJeune, Patricia Taylor-Cooke, Sherry Mullinix Pryor, Erin Hundley, and Elizabeth "Raven" Cuellar for their assistance with data collection and database management.

\section{REFERENCES}

Abramson, M., Ash, M.J., \& Nash, W.R. (1979). Handicapped adolescents-a time for reflection. Adolescence, 14(55), 557-565.

Achenbach, T.M. \& Rescorla, L.A. (2001). Manual for the ASEBA School-Age Forms \& Profiles. Burlington, VT: University of Vermont, Research Center for Children, Youth, and Families.

Aldrich, E.F., Eisenberg, H.M., Saydjara, C., Luerssen, T.G., Foulkes, M.A., \& Jane, J.A. (1992). Diffuse brain swelling in severely head injured children: A report from the NIH Traumatic Coma Data Bank. Journal of Neurosurgery, 76, 450-454.

Amieva, H., Lafont, S., Auriacombe, S., Rainville, C., Orgogozo, J.M., Dartigues, J.F., \& Fabrigoule, C. (1998). Analysis of error types in the Trail Making Test evidences inhibitory deficit in dementia of the Alzheimer type. Journal of Clinical and Experimental Neuropsychology, 20, 280-285.

Austin, J.K. \& Huberty, T.J. (1989). Revision of the Family APGAR for use by 8 year olds. Family Systems Medicine, 3, 323-327.

Barf, H.A., Verhoef, M., Jennekens-Schinkel, A., Post, M.W., Gooskens, R.H., \& Prevo, A.J. (2003). Cognitive status of young adults with spina bifida. Developmental Medicine and Child Neurology, 45, 813-820

Barnes, M.A., Wilkinson, M., Khemani, E., Boudesquie, A., Dennis, M., \& Fletcher, J.M. (2006). Arithmetic processing in children with spina bifida: Calculation accuracy, strategy use, and fact retrieval fluency. Journal of Learning Disabilities, 39, 174-187.

Baron, R.M. \& Kenny, D.A. (1986). The moderator-mediator variable distinction in social psychological research: Conceptual, strategic, and statistical considerations. Journal of Personality and Social Psychology, 51, 1173-1182.

Bartonek, A., Saraste, H., \& Knutson, L.M. (1999). Comparison of different systems to classify the neurological level of lesion 
in patients with myelomeningocele. Developmental Medicine and Child Neurology, 41, 796-805.

Bergsten, M. \& Lagergren, J. (1990). Life conditions of adolescents with myelomeningocele. Developmental Medicine and Child Neurology, 32, 698-706.

Bernat, D.H. \& Resnick, M.D. (2006). Healthy youth development: Science and strategies. Journal of Public Health Management and Practice, Suppl, S10-S16.

Bowman, R.M., McLone, D.G., Grant, J.A., Tomita, T., \& Ito, J.A. (2001). Spina bifida outcome: A 25-year prospective. Pediatric Neurosurgery, 34, 114-120.

Buran, C.F., Sawin, K.J., Brei, T.J., \& Fastenau, P.S. (2004). Adolescents with myelomeningocele: Activities, beliefs, expectations, and perceptions. Developmental Medicine and Child Neurology, 46, 244-252.

Burmeister, R., Hannay, H.J., Copeland, K., Fletcher, J.M., Boudousquie, A., \& Dennis, M. (2005). Attention problems and executive functions in children with spina bifida and hydrocephalus. Child Neuropsychology, 11, 265-283.

Conners, C.K. (1995). Conner's continuous performance test. Tonawanda, NY: Multi Health Systems Inc.

Davidovitch, M., Manning-Courtney, P., Hartmann, L.A., Watson, J., Lutkenhoff, M., \& Oppenheimer, S. (1999). The prevalence of attention problems and the effect of methylphenidate in children with myelomeningocele. Pediatric Rehabilitation, 3, 29-35.

Davidson, M.C., Amso, D., Anderson, L.C., \& Diamond, A. (2006). Development of cognitive control and executive functions from 4-13 years: Evidence from manipulations of memory, inhibition, and task switching. Neuropsychologia, 44, 2037-2078.

Davis, B.E., Shurtleff, D.B., Walker, W.O., Seidel, K.D., \& Duguay, S. (2006). Acquisition of autonomy skills in adolescents with myelomeningocele. Developmental Medicine and Child Neurology, 48, 253-258.

Dennis, M. (1985). Intelligence after early brain injury: II. IQ scores of subjects classified on the basis of medical history variables. Journal of Clinical and Experimental Neuropsychology, 7, 555-576.

Dennis, M. \& Barnes, M. (2002). Math and numeracy in young adults with spina bifida and hydrocephalus. Developmental Neuropsychology, 21, 141-155.

Dennis, M., Landry, S.H., Barnes, M., \& Fletcher, J.M. (2006). A model of neurocognitive function in spina bifida over the lifespan. Journal of the International Neuropsychological Society, 45, 285-296.

Dise, J.E. \& Lohr, M.E. (1998). Examination of deficits in conceptual reasoning abilities associated with spina bifida. American Journal of Physical Medicine and Rehabilitation, 77, 247-251.

Donders, J., Rourke, B.P., \& Canady, A.I. (1991). Neuropsychological functioning of hydrocephalic children. Journal of Clinical and Experimental Neuropsychology, 13, 607-613.

Duquette, A.M. (1997). Adaptation: A concept analysis. The Journal of School Nursing, 13, 30-33.

Fastenau, P.S., Shen, J., Dunn, D.W., Perkins, S.M., Hermann, B.P., \& Austin, J.K. (2004). Neuropsychological predictors of academic underachievement in pediatric epilepsy: Moderating roles of demographic, seizure, and psychosocial variables. Epilepsia, 45, 1261-1272.

Fennell, E.B., Eisenstadt, T., Bodiford, C., Redeiss, S., \& Mickle, J. (1987). The assessment of neuropsychological dysfunction in children shunted for hydrocephalus. Journal of Clinical and Experimental Neuropsychology, 9, 25-26.

Fletcher, J.M., Bohan, T.P., Brandt, M.E., Brookshire, B.L., Beaver, S.R., Francis, D.J., Davidson, K.C., Thompson, N.M., \& Miner, M.E. (1992). Cerebral white matter and cognition in hydrocephalic children. Archives of Neurology, 49, 818-824.

Fletcher, J.M., Copeland, K., Frederick, J.A., Blaser, S.E., Kramer, L.A., Northrup, H., Hannay, H.J., Brandt, M.E., Francis, D.J., Villarreal, G., Drake, J.M., Laurent, J.P., Townsend, I., Inwood, S., Boudousquie, A., \& Dennis, M. (2005). Spinal lesion level in spina bifida: A source of neural and cognitive heterogeneity. Journal of Neurosurgery, 102(Suppl.), 268-279.

Fletcher, J.M., McCauley, S.R., Brandt, M.E., Bohan, T.P., Kramer, L.A., Francis, D.J., Thorstad, K., \& Brookshire, B.L. (1996). Regional brain tissue composition in children with hydrocephalus. Relationships with cognitive development. Archives of Neurology, 53, 549-557.

Friedrich, W.N., Lovejoy, M.C., Shaffer, J., Shurtleff, D.B., \& Beilke, R.L. (1991). Cognitive abilities and achievement status of children with myelomeningocele: A contemporary sample. Journal of Pediatric Psychology, 16, 423-428.

Galli, M., Albertini, G., Romei, M., Santambrogio, G.C., Tenore, N., \& Crivellini, M. (2002). Gait analysis in children affected by myelomeningocele: Comparison of the various levels of lesion. Functional Neurology, 17, 203-210.

Heaton, R.K., Chelune, G.J., Talley, J.L., Kay, G.G., \& Curtiss, G. (1993). Wisconsin Card Sorting Test Manual: Revised and Expanded. Odessa, Fl: Psychological Assessment Resources.

Holmbeck, G.N. \& Faier-Routman, J. (1995). Spinal lesion level, shunt status, family relationships, and psychosocial adjustment in children and adolescents with spina bifida myelomeningocele. Journal of Pediatric Psychology, 20, 817-832.

Hunt, G.M., Oakeshott, P., \& Kerry, S. (1999). Link between the CSF shunt and achievement in adults with spina bifida. Journal of Neurology, Neurosurgery, \& Psychiatry, 67, 591-595.

Hunt, G.M. \& Poulton, A. (1995). Open spina bifida: A complete cohort reviewed 25 years after closure. Developmental Medicine \& Child Neurology, 37, 19-29.

Iddon, J.L., Morgan, D.J., Loveday, C., Sahakian, B.J., \& Pickard, J.D. (2004). Neuropsychological profile of young adults with spina bifida with or without hydrocephalus. Journal of Neurology, Neurosurgery, and Psychiatry, 75, 1112-1118.

Iddon, J.L., Morgan, D.J., \& Sahakian, B.J. (1996). Cognitive dysfunction in patients with congenital hydrocephalus and spina bifida: Evidence for a dysexecutive syndrome? European Journal of Pediatric Surgery, 6(Suppl. 1), 41.

Kaufman, A. \& Kaufman, N. (1990). Kaufman Brief Intelligence Test. Circle Pines, MN: American Guidance Service.

Kim, W.J. (1991). Psychiatric aspects of epileptic children and adolescents. Journal of the American Academy of Child and Adolescent Psychiatry, 30, 874-886.

King, G.A., Shultz, I.Z., Steel, K., Gilpin, M., \& Cathers, T. (1993). Self-evaluation and self-concept of adolescents with physical disabilities. American Journal of Occupational Therapy, 47, 132-140.

Landry, S.H., Robinson, S.S., Copeland, D., \& Garner, P.W. (1993). Goal-directed behavior and perception of self-competence in children with spina bifida. Journal of Pediatric Psychology, 18, 389-396.

Larsson, G. (1995). School-based treatment of recurrent headaches in adolescents. In J.L. Wallander \& L.J. Siegel (Eds.), 
Adolescent Health Problems (pp. 248-264). New York, NY: The Guilford Press.

Lomax-Bream, L.E., Barnes, M., Copeland, K., Taylor, H.B., \& Landry, S.H. (2007). The impact of spina bifida on development across the first 3 years. Developmental Neuropsychology, 31, 1-20.

Loomis, J.W., Javornisky, J.M., Monahan, J.J., Burke, G., \& Lindsay, A. (1997). Relations between family environment and adjustment outcomes in young adults with spina bifida. Developmental Medicine and Child Neurology, 39, 620-627.

Loss, N., Yeates, K.O., \& Enrile, B.G. (1998). Attention in children with myelomeningocele. Child Neuropsychology, 4, 7-20.

Masten, A.S. \& Coatsworth, J.D. (1998). The development of competence in favorable and unfavorable environments: Lessons from research on successful children. American Psychologist, 53, 205-220.

Matson, M.A., Mahone, E.M., \& Zabel, T.A. (2005). Serial neuropsychological assessment and evidence of shunt malfunction in spina bifida: A longitudinal case study. Child Neuropsychology, 11, 315-332.

McAndrew, I. (1979). Adolescents and young people with spina bifida. Developmental Medicine and Child Neurology, 21, 619-629.

McCubbin, H.I., Thompson, A.I., \& McCubbin, M.A. (1996). Family Assessment: Resiliency, Coping, and Adaptation. Inventories for Research and Practice (2nd ed.). Madison, WI: University of Wisconsin System.

Monsen, R.B. (1992). Autonomy, coping, and self-care agency in healthy adolescents and in adolescents with spina bifida. Journal of Pediatric Nursing, 7, 9-13.

Msall, M.E., DiGaudio, K., Rogers, B.T., LaForest, S., Catanzaro, N.L., Campbell, J., Wilczenski, F., \& Duffy, L.C. (1994). The Functional Independence Measure for Children (WeeFIM): Conceptual basis and pilot use in children with developmental disabilities. Clinical Pediatrics, 33, 421-430.

Pless, I.B. (1984). Clinical assessment: Physical and psychological functioning. Pediatric Clinics of North America, 31, 33-45.

Prigatano, G.P., Zeiner, H.K., Pollay, M., \& Kaplan, R.J. (1983). Neuropsychological functioning in children with shunted uncomplicated hydrocephalus. Child's Brain, 10, 112-120.

Reitan, R.M. \& Wolfson, D. (1992). Neuropsychological Evaluation of Older Children. Tucson, AZ: Neuropsychology Press.

Resnick, M.D. \& Hutton, L. (1987). Resilience among physically disabled adolescents. Psychiatric Annals, 17, 796-800.

Resnick, M.D., Ireland, M., \& Borowsky, I. (2004). Youth violence perpetration: What protects? What predicts? Findings from the National Longitudinal Study of Adolescent Health. Journal of Adolescent Health, 35, 424.e421-e410.

Romine, C.B., Lee, D., Wolfe, M.E., Homack, S., George, C., \& Riccio, C.A. (2004). Wisconsin Card Sorting Test with children: A meta-analytic study of sensitivity and specificity. Archives of Clinical Neuropsychology, 19, 1027-1041.

Rutter, M. (1985). Resilience in the face of adversity: Protective factors and resistance to psychiatric disorders. British Journal of Psychiatry, 147, 598-611.

Rutter, M. (1987). Psychosocial resilience and protective mechanisms. American Journal of Orthopsychiatry, 57, 316-331.

Sawin, K.J., Bellin, M.H., Roux, G., Buran, C.F., Brei, T.J., \& Fastenau, P.S. (2003a). The experience of parenting an adolescent with spina bifida. Rehabilitation Nursing, 28, 173-185.

Sawin, K.J., Brei, T.J., Buran, C.F., \& Fastenau, P.S. (2002). Factors associated with quality of life in adolescents with spina bifida. Journal of Holistic Nursing, 20, 279-304.
Sawin, K.J., Buran, C.F., Brei, T.J., \& Fastenau, P.S. (2003b). Correlates of functional status, self-management, and developmental competence outcomes in adolescents with spina bifida. $S C I$ Nursing, 20, 72-85.

Sawin, K.J., Hayden Bellin, M., Builta, E., Vasel, L., Buran, C.F., \& Brei, T.J. (2006). Cross-informant agreement between adolescents with myelomeningocele and their parents. Developmental Medicine and Child Neurology, 48, 188-194.

Sawin, K.J. \& Marshall, J. (1992). Developmental competence in adolescents with an acquired disability. Rehabilitation Nursing Research, 1, 41-50.

Sawin, K.J., Metzger, S.G., \& Pellock, J.M. (1996). The experience of living with epilepsy from an adolescent and parent perspective. Epelipsia, 37(Suppl. 5), 86.

Scott, M.A., Fletcher, J.M., Brookshire, B.L., Davidson, K.C., Landry, S.H., Bohan, T.C., Kramer, L.A., Brandt, M.E., \& Francis, D.J. (1998). Memory functions in children with early hydrocephalus. Neuropsychology, 12, 578-589.

Shurtleff, D.B. (2000). 44 years experience with management of myelomeningocele: Presidential address, Society for Research into Hydrocephalus and Spina Bifida. European Journal of Pediatric Surgery, 10(Suppl. 1), 5-8.

Smilkstein, G. (1993). Family APGAR analyzed. Family Medicine, 25, 293-294.

Smilkstein, G., Ashworth, C., \& Montano, D. (1982). Validity and reliability of family APGAR as a test of family function. The Journal of Family Practice, 15, 303-311.

Snow, J.H. (1999). Executive processes for children with spina bifida. Children's Health Care, 28, 241-253.

Snow, J.H., Prince, M., Souheaver, G., Ashcraft, E., Stefans, V., \& Edmonds, J. (1994). Neuropsychological patterns of adolescents and young adults with spina bifida. Archives of Clinical Neuropsychology, 9, 277-287.

Snyder, C.R., Harris, C., Anderson, J.R., Holleran, S.A., Irving, L.M., Sigmon, S.T., Yoshinobu, L., Gibb, J., Langelle, C., \& Harney, P. (1991). The will and the ways: Development and validation of an individual-differences measure of hope. Journal of Personality and Social Psychology, 60, 570-585.

Sobel, M.E. (1982). Asymptotic intervals for indirect effects in structural equations models. In S.L. Leinhart (Ed.), Sociological Methodology (pp. 290-312). San Francisco: JosseyBass.

Stevenson, C.J., Pharoah, P.O., \& Stevenson, R. (1997). Cerebral palsy-the transition from youth to adulthood. Developmental Medicine and Child Neurology, 39, 336-342.

Thompson, N.M., Fletcher, J.M., Chapieski, L., Landry, S.H., Miner, M.E., \& Bixby, J. (1991). Cognitive and motor abilities in preschool hydrocephalics. Journal of Clinical and Experimental Neuropsychology, 13, 245-258.

Unified Data Systems. (2000). WeeFIM Manual. Buffalo, NY: Unified Data Systems.

Voll, R., Mayer, U., Krumm, B., \& Fichtner, H. (1995). Coping in young people with spina bifida and traumatic paraplegia: An empirical investigation. Rehabilitation, 34, 8-15.

Wallander, J.L. \& Thompson, R.J.J. (1995). Psychosocial adjustment of children with chronic physical conditions. In M.C. Roberts (Ed.), Handbook of Pediatric Psychology (2 ed., pp. 124-141). New York: The Guilford Press.

Wallander, J.L. \& Varni, J.W. (1995). Appraisal, coping, and adjustment in adolescents with a physical disability. In J.L. Wallander \& L.J. Siegel (Eds.), Adolescent Health Problems (pp. 209-231). New York, NY: The Guilford Press. 
Wechsler, D. (1991). Wechsler Intelligence Scale for ChildrenThird Edition (WISC-III). San Antonio, TX: The Psychological Corporation.

West, M., Fjeldvik, L., \& Rand-Hendricksen, S. (1995). Cognitive deficits often seen in young adults with spina bifida. European Journal of Pediatric Surgery, 5(Suppl. 1), 12-15.

Wills, K.E., Holmbeck, G.N., Dillon, K., \& McLone, D.G. (1990). Intelligence and achievement in children with myelomeningocele. Journal of Pediatric Psychology, 15, 161-176.

Wolman, C., Resnick, M.D., Harris, L.J., \& Blum, R.W. (1994). Emotional well-being among adolescents with and without chronic conditions. Journal of Adolescent Health, 15, 199-204.

Yeates, K.O., Enrile, B.G., Loss, N., Blumenstein, E., \& Delis, D.C. (1995). Verbal learning and memory in children with myelomeningocele. Journal of Pediatric Psychology, 20, 801-815.
Zauszniewski, J.A. (1995). Theoretical and empirical considerations of resourcefulness. Image - The Journal of Nursing Scholarship, 27, 177-180.

Ziviani, J., Ottenbacher, K.J., Shephard, K., Foreman, S., Astbury, W., \& Ireland, P. (2001). Concurrent validity of the Functional Independence Measure for Children (WeeFIM) and the Pediatric Evaluation of Disabilities Inventory in children with developmental disabilities and acquired brain injuries. Physical and Occupational Therapy in Pediatrics, 21, 91-101.

Zurmohle, U.M., Homann, T., Schroeter, C., Rothgerber, H., Hommel, G., \& Ermert, J.A. (1998). Psychosocial adjustment of children with spina bifida. Journal of Child Neurology, 13 $64-70$. 